\title{
Treatment Options for Patients with Type 2 Diabetes Mellitus during the Fasting Month of Ramadan
}

Huai Heng Loh, ${ }^{1}$ MBBS, MRCP, Nor Azmi Kamaruddin, ${ }^{2}$ MMed, FACE, FAMM

\begin{abstract}
During Ramadan, Muslims fast from sunrise (Sahur) to sunset (Iftar) and are required to abstain from food and fluids, including oral and injectable medications. Patients with diabetes who fast during Ramadan are at risk of developing hyperglycemia with increased risk of ketoacidosis, hypoglycemia, dehydration and thrombosis. Pre-Ramadan education and preparation of a fasting patient are essential to reduce severe complications. This review paper summarizes studies to date on oral and injectable medications available for patients with type 2 diabetes during Ramadan fasting, as well as recommendations on management of these patients during Ramadan. Although there is limited data on the use of Metformin, Acarbose and Thiazolidinedione in Ramadan, they appear to be safe. Sulphonylurea, especially Glibenclamide, is associated with higher risk of hypoglycemia during Ramadan fasting, hence may need adjustment in dosing and timing. The incretin group and SGLT2 inhibitor use during Ramadan fasting is associated with low risk of hypoglycemia with no increased adverse events. Insulin regimes need to be individualized for patients who fast during Ramadan.
\end{abstract}

Ann Acad Med Singapore 2020;49:468-76

Key words: Anti-diabetic medication dose adjustment; Iftar (sunset), Muslims; Sahur (sunrise); Treatment modification

\section{Case Study}

$A$ is a 49-year old gentleman who has type 2 diabetes (T2D), hypertension and dyslipidaemia for 8 years. His treatment for T2D are Metformin $1 \mathrm{~g}$ b.d., Gliclazide $160 \mathrm{mg}$ b.d. and nocturnal s/c Insulatard $12 u$. His body mass index is $30.8 \mathrm{~kg} / \mathrm{m}^{2}$. His latest blood results reveal $\mathrm{HbA} 1 \mathrm{c}$ of $8.6 \%$, fasting blood glucose $7.5 \mathrm{mmol} / \mathrm{L}$, creatinine $118 \mathrm{umol} / \mathrm{L}$. During the previous Ramadan, he experienced a few episodes of hypoglycaemia, requiring him to break his fast. He wishes to fast for this Ramadan.

\section{Introduction}

Ramadan fasting is one of the 5 pillars of Islam. The fast is between sunrise (Sahur) and sunset (Iftar), i.e. the start of the fast is at sunrise and it ends at sunset; essentially during the period of daytime. During the fast, Muslims are required to abstain from food (including fluids), as well as oral and injectable medications. The estimated number of diabetic Muslims who choose to fast every year is close to 150 million worldwide, ${ }^{1}$ which makes it one of the most challenging conditions to manage.

Prolonged fasting in a patient with T2D is associated with increased medical risks, especially hyperglycaemia, hypoglycaemia, dehydration and thrombosis. Nevertheless, despite these risks and the fact that patients with T2D are exempted from fasting, the majority of Muslim diabetic patients still choose to

${ }^{1}$ Department of Medicine, Faculty of Medicine and Health Sciences, Universiti Malaysia Sarawak, Malaysia

${ }^{2}$ Department of Medicine, Faculty of Medicine, Universiti Kebangsaan Malaysia Medical Center, Malaysia

Address for Correspondence: Dr Huai Heng Loh, Department of Medicine, Faculty of Medicine and Health Sciences, Universiti Malaysia Sarawak, Jalan Datuk Mohd Musa, Kota Samarahan 94300, Malaysia

Email: hhloh@unimas.my 
fast during Ramadan. The EPIDIAR and CREED studies indicated that $80-90 \%$ of Muslims with T2D fasted more than 15 days, with up to two-thirds of the participants fasting every day during Ramadan., ${ }^{2,3}$

\section{Pre-Ramadan preparations and education}

Fasting during Ramadan is important to Muslims as it is a deeply spiritual experience, allowing them to devote themselves to their faith. Besides, it is also shown to confer metabolic and glycaemic benefits. ${ }^{4}$ It can be practised safely with early preparations, advice, guidance, and effective pre-Ramadan education. ${ }^{5}$ It has been shown that patients who did not receive adequate education prior to Ramadan had an increased risk of hypoglycaemia during fasting compared to those who did. ${ }^{6}$

One of the key components in a Ramadan-focused educational program is to quantify and stratify the patients' risks if they choose to fast (Table 1). In A's case, illustrated above, the experience of prior hypoglycaemia episodes during previous fasting and $\mathrm{HbA} 1 \mathrm{c}$ of $8.6 \%$ put him in the high-risk category, and he should be advised against fasting. Generally, risk stratification is based on several factors. Among these are the presence of concomitant comorbidities or diabetes-related complications such as renal failure, and patient's hypoglycaemia risk. These factors may increase adverse events during Ramadan and high-risk patients are strongly advised against prolonged fasting. ${ }^{5}$
However, the patients' wish to fast must be respected, hence the importance of a more structured Ramadanfocused care and support for them. A should be advised to monitor his blood glucose more regularly, and to look out for hypoglycaemic symptoms, as illustrated in Table 2. He should be advised to take plenty of non-caloric fluids during the non-fasting period to avoid dehydration and thrombosis. He should also adhere to standard dietary advice, such as avoiding sugary desserts and not skipping meals during Sahur (sunrise). Light to moderate intensity exercises are encouraged on a regular basis, and should be performed preferably 1-2 hours post-Iftar (sunset). ${ }^{7}$ Very importantly, A should be educated on the symptoms of hypoglycaemia, hyperglycaemia, dehydration, when to break the fast, and the management of acute complications.

It is important to note that most medications that the patients are on, prior to Ramadan, can be continued with safely or have their dosages adjusted during Ramadan. Nevertheless, a few newer agents may have less potential for hypoglycaemia and be beneficial to patients during Ramadan. We present here a summary of studies, to date, on the available oral and injectable medications for patients with T2D.

\section{Oral Anti-diabetic agents (OAD)}

\section{Metformin}

Metformin, which reduces hepatic gluconeogenesis, is the first line agent for patients with $\mathrm{T} 2 \mathrm{D}$, and should

Table 1. Risk Stratification of Patients with Type 2 Diabetes Prior to Ramadan Fasting (Adapted with permission from Practical Guide to Diabetes Management in $\operatorname{Ramadan}^{7}$ )

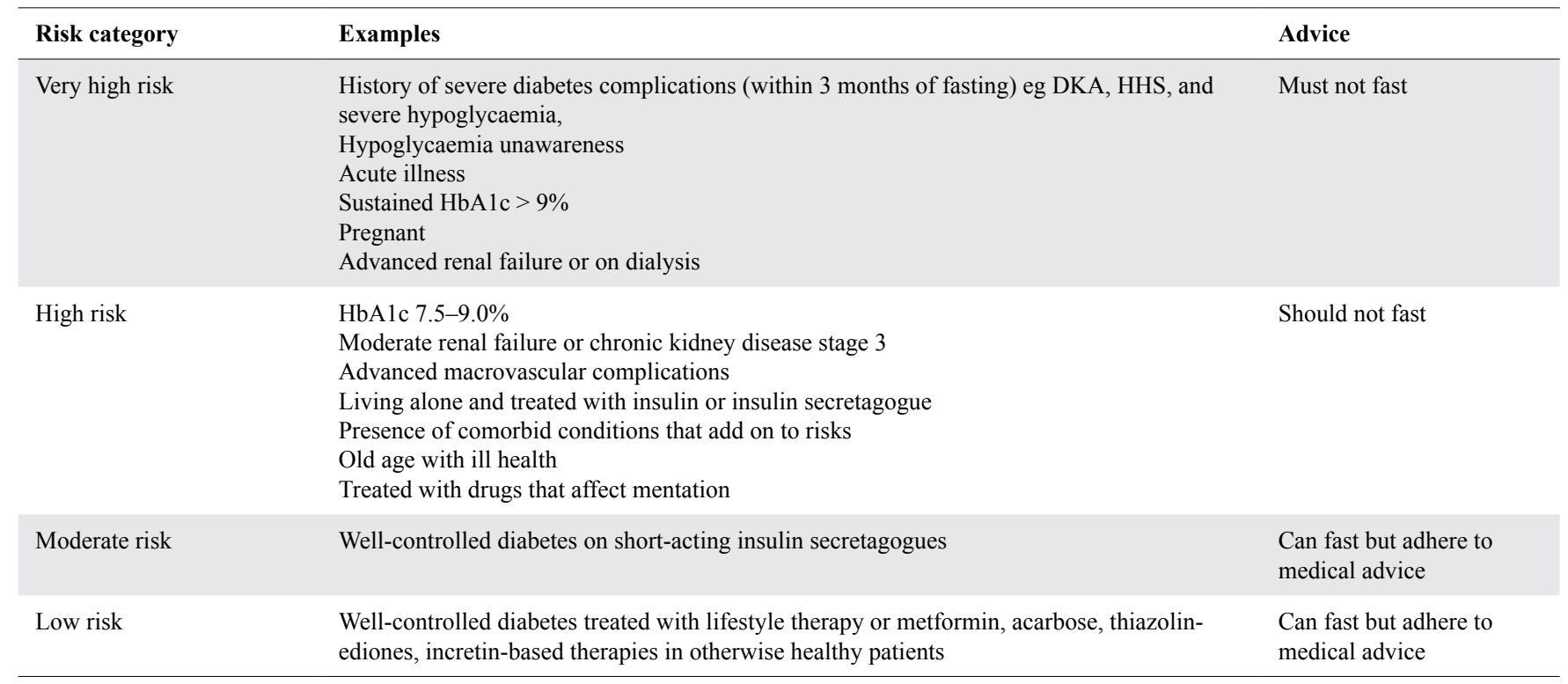


Table 2. Home Glucose Monitoring Guide Among Patients with Type 2 Diabetes Who Fast During Ramadan (Adapted with permission from Practical Guide to Diabetes Management in $\operatorname{Ramadan}^{7}$ )

\begin{tabular}{lcc}
\hline Time & Reflection of insulin & Very high risk/high risk \\
\hline Pre-sahur (sunrise) & Pre-iftar (sunset)/pre-bed & $\sqrt{ }$ \\
\hline 2 hours post-sahur (sunrise) & Pre-sahur (sunrise) & $\sqrt{ }$ \\
Mid-day & Pre-sahur (sunrise) & $\sqrt{ }$ \\
Pre-iftar (sunset) & Pre-sahur (sunrise) & $\sqrt{ }$ \\
2 hours post-iftar (sunset) & Pre-iftar (sunset) & $\sqrt{ }$ \\
\hline Hypoglycaemic symptoms & & $\sqrt{ }$ \\
\hline
\end{tabular}

be duly prescribed, unless it is contraindicated. Unfortunately, there are no randomised controlled trials (RCT) looking at the effect of Metformin monotherapy during Ramadan. There are, however, studies of Metformin in combination with dipeptidyl peptidase 4 (DPP-4) inhibitors and sodium-glucose co-transporter 2 (SGLT2) inhibitors, which have shown low hypoglycaemic risks, good HbAlc reduction, no increased adverse events and better weight control, compared to the combination of Metformin with Sulphonylureas (SU). ${ }^{8-14}$

\section{Alpha-glucosidase Inhibitor (AGI)}

AGI acts by reducing or delaying carbohydrate digestion by competitive alpha-glucosidase enzyme inhibition at the brush border of gut epithelium, without stimulating insulin release. There are no RCTs available on the effect of AGI during Ramadan. However, in a non-fasting group, it is associated with low hypoglycaemic risks with the added benefit of mild weight loss, absent cardiovascular sequelae with modest HbAlc reduction of $0.4-0.6 \% .{ }^{15-19}$ It may, however, be limited by its gastrointestinal side effects, especially after a heavy carbohydrate intake seen during the breaking of fast. ${ }^{20-22}$ On the other hand, the twicedaily dosing during Ramadan (with the omission of lunch dose) may reduce its gastrointestinal side effects, which are dose-dependent.

\section{Thiazolidinedione (TZD)}

This class of drug is an insulin sensitiser, which acts by increasing glucose absorption into the adipose tissue and muscle, plus decreasing gluconeogenesis in the liver. Pioglitazone is the most widely-approved and used TZD in patients with T2D at the moment. ${ }^{23}$ There is only
1 study that looked at the effect of this drug during Ramadan, which showed no significant difference in hypoglycaemic episodes between the 2 arms. $^{24}$ Pioglitazone showed better glycaemic control throughout the study period, as evidenced by the lower stable fructosamine values. However, pioglitazone users experienced more weight gain and oedema (mean weight gain $3.02 \mathrm{~kg}, P=0.001$ ), compared to those who received placebo.

\section{Insulin Secretagogue}

SU and Metglinides act by stimulating the pancreatic $\beta$-cells to produce insulin in a glucose-independent manner, and hence are associated with higher risks of hypoglycaemia. Despite that, SU is the most commonly prescribed OAD during Ramadan in most countries, ${ }^{3}$ probably owing to its affordability as well as glycaemic efficacy. Both drugs are estimated to reduce $\mathrm{HbA} 1 \mathrm{c}$ by $1-2 \%$, compared to placebo in nonfasting population. ${ }^{25,26}$

When compared to Glibenclamide, Repaglinide showed better glycaemic efficacy with lower midday hypoglycaemic events. ${ }^{27}$ However, shorter-acting SUs (Glimiperide and Gliclazide) showed comparable glycaemic control with minimal hypoglycaemic events, when compared with Repaglinide. ${ }^{28}$ Indeed, in an observational study during Ramadan, SU users who were prescribed Glibenclamide reported the highest incidence of severe hypoglycaemia compared to those who were on Glimepiride or Gliclazide. ${ }^{29}$ Lowering the dose of Glibenclamide did not seem to reduce hypoglycaemic events during Ramadan. ${ }^{30}$ There were several other studies which compared other classes of drugs to $\mathrm{SU}$, and these will be covered in the later sections. 


\section{DPP-4 Inhibitor}

DPP-4 inhibitor acts by inhibiting the DPP-4 enzyme which inactivates the incretin hormones, thereby prolonging the effects of glucagon-like peptide 1 (GLP-1) and glucose-dependent insulinotropic polypeptide (GIP) in stimulating the pancreatic $\beta$-cells to secrete insulin, and suppressing $\alpha$-cells from producing glucagon. As DPP-4 inhibitor acts in a glucose-dependent manner, the risk of hypoglycaemia is low.

There are currently 4 RCTs and 6 observational studies examining the effects of DPP-4 inhibitor during Ramadan. The majority used Vildagliptin and 2 of them used Sitagliptin as the choice of DPP-4 inhibitor. The comparator group for all the studies was SU. In one of the larger RCTs examining Vildagliptin versus Gliclazide in patients on a background of Metformin therapy, there was no significant difference in glycaemic control in both arms $(P=0.165$ for between-group difference). ${ }^{12}$ Those prescribed with Vildagliptin had significantly lower confirmed hypoglycaemic events compared to the Gliclazide group (3.0\% versus $7.0 \%$, $P=0.039)$. Overall, no severe hypoglycaemic events were reported. Even patients with longer duration of T2D (mean 7.1 years \pm 3.1 years) with suboptimal control (mean HbA1c 8.98\% $\pm 0.37 \%$ ) prescribed with Vildagliptin during Ramadan showed significantly lower hypoglycaemic events compared to the Gliclazide group $(7.7 \%$ versus $61.5 \%, P<0.001){ }^{31}$ In a multicentre observational study examining Vildagliptin versus SUs, which included Glibenclamide, significantly fewer patients from the Vildagliptin arm experienced hypoglycaemic events compared to the SU arm (5.4\% versus $19.8 \%, P<0.001) .{ }^{32}$ While there were no reports of severe hypoglycaemic events from those receiving Vildagliptin, 4 patients receiving SU reported such events, although it only achieved borderline significance $(P=0.053)$. A sub-analysis showed Glibenclamide contributed to the highest proportion $(31.8 \%)$ of hypoglycaemic events, followed by Gliclazide (19.2\%), Glimepiride (17.9\%), and Glipizide (12.5\%). In this study, Vildagliptin arm achieved better HbA1c reduction compared to $\mathrm{SU}$ (between-treatment difference $-0.26 \%, P<0.001)$ and more weight loss (between treatment difference $-0.63 \mathrm{~kg}, P<0.001$ ). As Vildagliptin is associated with a lower risk of hypoglycaemia, treatment adherence was higher when compared to insulin secretagogue. The proportion of patients missing more than 5 doses during Ramadan was lower in Vildagliptin arm $(8.5 \%)$ than in the SU $\operatorname{arm}(15.4 \%) .{ }^{10}$
In the largest RCT available, comparing Sitagliptin $(n=507)$ and SU $(n=514)$, a lower proportion of Sitagliptin users developed hypoglycaemia compared to those on $\mathrm{SU}(6.7 \%$ versus $13.2 \%, P<0.001) .{ }^{33}$ However, in the sub-group analysis, the highest proportion of hypoglycaemic events occurred in subjects who were on Glibenclamide (19.7\%). On the other hand, among those who were put on Gliclazide, the proportion who experienced hypoglycaemic events was similar to those in the Sitagliptin arm $(6.6 \%$ versus $6.7 \%$ ).

Other reported adverse events associated with Vildagliptin and Sitagliptin are fever, infection and gastrointestinal disturbances, but the numbers are relatively small. ${ }^{12,14,29,32-34}$

\section{SGLT2 Inhibitors}

This is the newest class of OAD for T2D, and is gaining popularity owing to the recently discovered cardiovascular and renal protection. ${ }^{35-41}$ It acts by inhibiting the SGLT2 receptors found mainly on the S1 segment of the proximal glomerular tubules, which are responsible for the reabsorption of glucose filtered through the kidneys back into the circulation. This inhibition leads to a loss of glucose in the urine, hence contributing to significant weight loss among SGLT2 inhibitor users. However, along with the glycosuria, other concerns arise, such as (i) dehydration due to osmotic diuresis, which may become a major concern in Ramadan fasting, (ii) infection, especially of the genitourinary tract, and (iii) euglycaemic ketoacidosis, brought about mainly by the subsequent reduction of insulin doses to prevent hypoglycaemia once SGLT2 inhibitor is started.

There are only 3 studies examining this class of drug during Ramadan. In an open-label study, by one of the authors, comparing Dapagliflozin versus SU, both comprising patients on background Metformin therapy, fewer patients in the Dapagliflozin arm experienced symptomatic $(3.4 \%$ versus $19.2 \%, P=0.008)$ or documented hypoglycaemia $(7.3 \%$ versus $27.1 \%$, $P=0.007)$ compared to SU users. ${ }^{9}$ Although there was a tendency for Dapagliflozin subjects to end up with adverse events such as genitourinary tract infection $(10.3 \%$ versus $3.8 \%, P=0.277)$ and postural hypotension $(13.8 \%$ versus $5.8 \%, P=0.210)$, there was no statistically significant difference when compared to the SU arm. There was comparable glycaemic control, assessed using serum fructosamine, fasting plasma glucose and $\mathrm{HbAlc}$ between pre- and post-Ramadan for both arms. In this study, the subjects 
who were randomised to SGLT2 inhibitor were specifically instructed to take the drug at the break of fast (Iftar) to avoid dehydration during the daytime fast.

In addition, Canagliflozin or Empagliflozin users, who have been on stable doses for at least 3 months prior to the study, did not exhibit a significant rise in $\beta$-hydroxybutyrate levels post-Ramadan. This translates to a minimal risk of developing ketosis with the use of these anti-diabetic agents during Ramadan fasting. ${ }^{42}$ In this study, there was also no statistically significant difference in the secondary end points between the SGLT2 inhibitor and the non-SGLT2 inhibitor arm, with respect to weight changes, systolic and diastolic blood pressures, fasting plasma glucose and estimated glomerular filtration rates. There were no increased hypoglycaemic events pre- and post-Ramadan in both arms, with no severe hypoglycaemic events reported.

In a real-world observational trial of 417 subjects treated with either Dapagliflozin or Canagliflozin on top of insulin or other OAD, $27.0 \%$ of SGLT2 inhibitor users developed hypoglycaemic events and 9.3\% had symptoms of dehydration during Ramadan, both seen among those who were concurrently treated with insulin. ${ }^{43}$

\section{GLP-1 Receptor Analogue (GLP-1RA)}

GLP-1RA is an attractive option in patients with T2D, owing to its extra benefit of weight loss by delaying gastric emptying. It is given at a supra-physiological dose and mimics incretin hormone GLP-1, which stimulates pancreatic $\beta$-cells to produce insulin and suppresses $\alpha$-cells from secreting glucagon in a glucosedependent manner, and hence is associated with a low risk of hypoglycaemia.

There are 2 available RCTs and one observational study examining the effects of GLP-1RA during Ramadan. TREAT 4 Ramadan is a 12-week trial where patients with T2D were randomised to receive either Liraglutide $1.2 \mathrm{mg}$ /day or SU, in addition to Metformin. ${ }^{44}$ The primary outcome was a composite endpoint of $\mathrm{HbAlc}<7.0 \%$ with no weight gain and no severe hypoglycaemic events. Although not statistically significant, more subjects in the Liraglutide arm tended to achieve the composite endpoints compared to SU users $(26.7 \%$ versus $10.3 \%, P=0.06)$ at 12 weeks post-Ramadan. When individual components were analysed, subjects who received Liraglutide achieved better $\mathrm{HbA} 1 \mathrm{c}$ reduction $(-0.54 \% \pm 0.87 \%$ versus $-0.27 \%$ $\pm 0.60 \%, P=0.03)$ and weight loss $(-2.23 \pm 2.96$ versus
$-0.42 \pm 1.57, P=0.02$ ) at 3 weeks post-Ramadan compared to the SU arm. Liraglutide users also had a lower risk of hypoglycaemic events compared to SU users. ${ }^{45}$ There were, however, significantly more patients experiencing gastrointestinal discomfort prior to Ramadan, especially during the dose escalation period, leading to withdrawal from the study. Hence, it is recommended that dose titration should be completed 6-8 weeks prior to Ramadan to reduce these adverse events. The sole observational study revealed $16.2 \%$ of hypoglycaemic events when Liraglutide of at least $1.2 \mathrm{mg}$ daily was added to on-going anti-diabetic agents among 111 participants during Ramadan. ${ }^{46}$ There were, however, no severe hypoglycaemic events requiring hospital admission. In this study, $94.6 \%$ of the participants were on either insulin or SU therapy.

A dose adjustment guide for non-insulin therapies in Ramadan is summarised in Table 3.

\section{Insulin}

For insulin-requiring patients with $\mathrm{T} 2 \mathrm{D}$, the commonly prescribed regimes are (i) once daily basal insulin with or without addition of prandial insulin, and (ii) pre-mixed insulin given twice daily. There is no guide on the ideal insulin regime for patients with T2D who fast during Ramadan, as the insulin regime ideally should be individualised according to the patient's profile. Suffice to say, analogue insulin differs from human soluble insulin in terms of the onset and duration of action, and hence is associated with a lower risk of hypoglycaemia, especially nocturnal hypoglycaemia. ${ }^{47}$ Unfortunately, there is no large RCT on insulin use in Ramadan.

There is no head-to-head trial comparing basal analogue insulin with human insulin. Observational studies of Glargine showed glycaemic efficacy and hypoglycaemic event rates to be comparable to those of Glimepiride and Repaglinide. ${ }^{48}$ This basal analogue insulin also appears to be safe when added to Repaglinide with no increased risk of hypoglycaemic events when studied in non-fasting population. However, this study is limited by its small sample size of 7 subjects per arm. ${ }^{49}$ When Glargine or Glimepiride was added to either insulin-naïve or subjects already receiving insulin prior to Ramadan in an observational study, glycaemic control improved and was maintained throughout Ramadan, with no significant difference in the risk of hypoglycaemia between the 2 arms. $^{50}$ The predictive factors for developing hypoglycaemia during Ramadan were found to be geographical area, weight $<70 \mathrm{~kg}$, waist 
Table 3. Dose and Timing Adjustment of Non-Insulin Treatment Options During Ramadan (Adapted with permission from Practical Guide to Diabetes Management in $\operatorname{Ramadan}^{7}$ )

\begin{tabular}{|c|c|c|}
\hline Anti-diabetic agent & & Dose change \\
\hline Biguanides & $\begin{array}{l}\text { IR twice daily } \\
\text { IR thrice daily } \\
\text { XR once daily }\end{array}$ & $\begin{array}{l}\text { No change } \\
2 / 3 \text { of dose pre-iftar (sunset), } 1 / 3 \text { of dose pre-sahur (sunrise) } \\
\text { No change }\end{array}$ \\
\hline Alpha glucosidase inhibitor & & No change \\
\hline Thiazolinediones & & No change \\
\hline Sulphonylurea & $\begin{array}{l}\text { Glibenclamide } \\
\text { Gliclazide twice daily } \\
\text { Gliclazide MR once daily } \\
\text { Glimepiride once daily }\end{array}$ & $\begin{array}{l}\text { Avoid } \\
\text { Reduce/omit pre-sahur (sunrise) dose, maintain pre-iftar (sunset) dose } \\
\text { Take at pre-iftar (sunset) } \\
\text { Take at pre-iftar (sunset) }\end{array}$ \\
\hline Glinides & & No change \\
\hline DPP-4 inhibitor & & No change \\
\hline SGLT2 inhibitor & & No change \\
\hline GLP-1 receptor analogue & & No change \\
\hline
\end{tabular}

circumference $<90 \mathrm{~cm}$ and well-controlled blood sugar levels prior to Ramadan.

In a recent study comparing 2 insulin analogues, IDegAsp and BIAsp 30, those who were given the ultra-long insulin basal analogue IDegAsp had $74 \%$ and $83 \%$ reduction in the rate of overall and nocturnal hypoglycaemia, respectively, compared with those given BIAsp 30, despite comparable glycaemic efficacy. ${ }^{51}$

When premixed analogue insulin was compared with premixed human insulin 30/70 in an open-label crossover study involving 151 participants, those who received analogue insulin had lower post-Iftar (sunset) blood sugar despite the use of identical mean doses of insulin for both arms. ${ }^{52}$ There was, however, no significant difference in hypoglycaemic events between the 2 groups.

In a non-inferiority trial evaluating a new insulin regime combining Levemir given pre-Sahur (sunrise) and Novomix 70 pre-Iftar (sunset) compared to the standard insulin regime, the pre-Iftar (sunset) blood sugar levels were lower in the control arm $(P=0.006)$, whereas the post-Iftar (sunset) blood sugar levels were lower in the intervention arm $(P<0.001){ }^{53}$ This translates to lower blood sugar excursion between pre- and post-Iftar (sunset) in the intervention arm. There were also significantly fewer subjects in the intervention arm who developed hypoglycaemia ( $4.8 \%$ versus $21.4 \%, P<0.001)$.
Similarly, in another study, subjects given rapid acting insulin pre-Iftar (sunset) showed lower 1 hour and 2 hour post-prandial blood glucose rise compared to when they were given short acting human insulin $(P<0.001)$ in a cross-over study involving 57 out patients. ${ }^{54}$

A summary of recommendations for insulin adjustments and dosing is shown in Tables 4 and 5 .

\section{Conclusion}

In summary, Muslim diabetic patients who belong to the high-risk and very high-risk categories should be advised against fasting during Ramadan to prevent severe acute diabetic complications. Nevertheless, for those who choose to fast, pre-Ramadan preparations and education are essential to reduce the risks of these complications. This group of patients should be advised on the timing and dose adjustments necessary during this crucial month..$^{55}$ There is limited data on the use of Metformin, Acarbose and TZD during Ramadan. However, they are associated with low risks of hypoglycaemia. SU, although widely used during Ramadan, is associated with higher risks of hypoglycaemia especially with Glibenclamide, which should be avoided, if possible, during Ramadan fasting. Shorter-acting SUs may need adjustments in terms of dosing and timing. Incretin therapies are associated with low risks of hypoglycaemia as they work in a glucose-dependent manner. Patients on DPP-4 inhibitors 
Table 4 Insulin Dose and Timing Changes during Ramadan (Adapted with permission from Practical Guide to Diabetes Management in Ramadan 7,55 )

\begin{tabular}{llll}
\hline Pre-Ramadan & During Ramadan & Note \\
\hline Prandial insulin & Pre-breakfast & Pre-sahur (sunrise) & May need dose reduction \\
& Pre-lunch & Omit & May need dose increment \\
& Pre-dinner & Pre-iftar (sunset) & \\
Basal insulin & Same time as pre-Ramadan & Reduce pre-sahur (sunrise) dose by 20-50\% \\
Pre-mixed insulin & Pre-breakfast given at pre-iftar (sunset) & Pre-dinner given at pre-sahur (sunrise) & Alternatch to basal bolus \\
\hline
\end{tabular}

Table 5 Insulin Dose Changes Every 3 Days Based on Home Glucose Monitoring during Ramadan (adapted with permission from Hassanein 2017 ${ }^{5}$ )

\begin{tabular}{ll}
\hline Fasting or pre-meals blood glucose, $\mathbf{~ m o l} / \mathbf{L}$ & Action (applies to prandial, basal or pre-mixed insulin) \\
\hline$<3.9$ or symptomatic & Break fast, hypoglycaemia management, reduce by $4 \mathrm{u}$ subsequently \\
\hline $4.0-<5$ & Reduce by $2 \mathrm{u}$ \\
\hline $5.0-7.0$ & Maintain same dose \\
$>7.0$ & Increase by $2 \mathrm{u}$ \\
$>16.6$ & Break fast, check for ketones, increase by $4 \mathrm{u}$ subsequently \\
\hline
\end{tabular}

have lower risks of hypoglycaemia, with similar glycaemic efficacy, compared to SU during Ramadan. Hence, DPP-4 inhibitors may be a more suitable and attractive treatment option among patients with higher risks of hypoglycaemia, especially elderly patients, those with renal impairment, those with periods of erratic food intake and those with history of hypoglycaemia during fasting while on SU. SGLT2 inhibitor is associated with low risks of hypoglycaemia with no increased adverse events. Insulin analogue is generally associated with a lower risk of hypoglycaemia compared to human soluble insulin with comparable glycaemic efficacies. However, the insulin regime for patients who fast during Ramadan needs to be individualised.

In the case of $\mathrm{A}$, diabetes treatment modification is necessary during Ramadan. Metformin can be safely continued as it is associated with low risks of hypoglycaemia. Basal insulin dose may need adjustments based on his fasting blood glucose levels. Gliclazide dose pre-Sahur (sunrise) needs to be reduced especially since he had experienced hypoglycaemic events during previous fasting. Alternatively, Gliclazide can be replaced with a DPP-4 inhibitor during Ramadan to avoid the risk of hypoglycaemia.

\section{REFERENCES}

1. Al-Arouj M, Assaad-Khalil S, Buse J, Fahdil I, Fahmy M, Hafez S, et al. Recommendations for management of diabetes during Ramadan: update 2010. Diabetes Care. 2010 Aug;33(8):1895-902.

2. Salti I, Benard E, Detournay B, Bianchi-Biscay M, Le Brigand C, Voinet $\mathrm{C}$, et al. A population-based study of diabetes and its characteristics during the fasting month of Ramadan in 13 countries: results of the epidemiology of diabetes and Ramadan 1422/2001 (EPIDIAR) study. Diabetes Care. 2004 Oct;27(10):2306-11.

3. Jabbar A, Hassanein M, Beshyah SA, Boye KS, Yu M, Babineaux SM. CREED study: Hypoglycaemia during Ramadan in individuals with Type 2 diabetes mellitus from three continents. Diabetes Res Clin Pract. 2017 Oct;132:19-26.

4. Yeoh EC, Zainudin SB, Loh WN, Chua CL, Fun S, Subramaniam T, et al. Fasting during Ramadan and Associated Changes in Glycaemia, Caloric Intake and Body Composition with Gender Differences in Singapore. Ann Acad Med Singapore. 2015 Jun;44(6):202-6.

5. Hassanein M, Al-Arouj M, Hamdy O, Bebakar WMW, Jabbar A, Al-Madani A, et al. Diabetes and Ramadan: Practical guidelines. Diabetes Res Clin Pract. 2017 Apr;126:303-16.

6. Bravis V, Hui E, Salih S, Mehar S, Hassanein M, Devendra D. Ramadan Education and Awareness in Diabetes (READ) programme for Muslims with Type 2 diabetes who fast during Ramadan. Diabet Med. 2010 Mar;27(3):327-31.

7. Md M, Zanariah H, Mohamad Wan Bebakar W, Hallaj Rahmatullah I, Azizah Aziz N, Shaffinaz Yusoff N, et al. Practical Guide to Diabetes Management in Ramadan; 2015.

8. Hemmingsen B, Schroll JB, Wetterslev J, Gluud C, Vaag A, Sonne DP, et al. Sulfonylurea versus metformin monotherapy in patients 
with type 2 diabetes: a Cochrane systematic review and meta-analysis of randomized clinical trials and trial sequential analysis. CMAJ Open. 2014 Jul;2(3):E162-75.

9. Wan Seman WJ, Kori N, Rajoo S, Othman H, Mohd Noor N, Wahab NA, et al. Switching from sulphonylurea to a sodium-glucose cotransporter2 inhibitor in the fasting month of Ramadan is associated with a reduction in hypoglycaemia. Diabetes Obes Metab. 2016 Jun; 18(6):628-32.

10. Halimi S, Levy M, Huet D, Quere S, Dejager S. Experience with Vildagliptin in Type 2 Diabetic Patients Fasting During Ramadan in France: Insights from the VERDI Study. Diabetes Ther. 2013 Dec;4(2):385-98.

11. Hassanein M, Hanif W, Malik W, Kamal A, Geransar P, Lister N, et al. Comparison of the dipeptidyl peptidase-4 inhibitor vildagliptin and the sulphonylurea gliclazide in combination with metformin, in Muslim patients with type 2 diabetes mellitus fasting during Ramadan: results of the VECTOR study. Curr Med Res Opin. $2011 \mathrm{Jul} ; 27(7): 1367-74$

12. Hassanein M, Abdallah K, Schweizer A. A double-blind, randomized trial, including frequent patient-physician contacts and Ramadan-focused advice, assessing vildagliptin and gliclazide in patients with type 2 diabetes fasting during Ramadan: the STEADFAST study. Vasc Health Risk Manag. 2014 May 28; $10: 319-26$.

13. Malha LP, Taan G, Zantout MS, Azar ST. Glycemic effects of vildagliptin in patients with type 2 diabetes before, during and after the period of fasting in Ramadan. Ther Adv Endocrinol Metab. 2014 Feb;5(1):3-9.

14. Shete A, Shaikh A, Nayeem KJ, Rodrigues L, Ali MS, Shah P, et al. Vildagliptin vs sulfonylurea in Indian Muslim diabetes patients fasting during Ramadan. World J Diabetes. 2013 Dec 15;4(6):358-64.

15. DiNicolantonio JJ, Bhutani J, O’Keefe JH. Acarbose: safe and effective for lowering postprandial hyperglycaemia and improving cardiovascular outcomes. Open Heart. 2015 Oct 19;2(1):e000327.

16. Kalra S, Sahay RK, Schnell O, Sheu WH, Grzeszczak W, Watada H, et al. Alpha-glucosidase inhibitor, acarbose, improves glycamic control and reduces body weight in type 2 diabetes: Findings on indian patients from the pooled data analysis. Indian J Endocrinol Metab. 2013;17(Suppl 1):S307-9.

17. Kalra S, Sahay RK, Schnell O, Sheu WH, Grzeszczak W, Watada H, et al. Acarbose improves glycemic control and reduces body weight: Subanalysis data of South Asia region. Indian J Endocrinol Metab. 2013;17(Suppl 1):S304-6.

18. Philip E, Sundaram ML, Das R, Chauhan SK, Deshpande S, Ambhore S, et al. Acarbose improves glycemic control as addon or monotherapy in Indian type-2 diabetes: Findings from the GlucoVIP multinational observational study. Indian J Endocrinol Metab. 2013 Dec;17(Supp1 3):S674-9.

19. Phillips P, Karrasch J, Scott R, Wilson D, Moses R. Acarbose improves glycemic control in overweight type 2 diabetic patients insufficiently treated with metformin. Diabetes Care. 2003 Feb;26(2):269-73.

20. Balfour JA, McTavish D. Acarbose. An update of its pharmacology and therapeutic use in diabetes mellitus. Drugs. 1993 Dec;46(6):1025-54.

21. Hotta N, Kakuta H, Sano T, Matsumae H, Yamada H, Kitazawa S, et al. Long-term effect of acarbose on glycaemic control in non-insulin- dependent diabetes mellitus: a placebo-controlled double-blind study. Diabet Med. 1993 Mar;10(2):134-8

22. Josse RG, Chiasson JL, Ryan EA, Lau DC, Ross SA, Yale JF, et al. Acarbose in the treatment of elderly patients with type 2 diabetes. Diabetes Res Clin Pract. 2003 Jan;59(1):37-42.

23. Kawaguchi-Suzuki M, Frye RF. Current clinical evidence on pioglitazone pharmacogenomics. Front Pharmacol. 2013 Nov 26;4:147.

24. Vasan S, Thomas N, Bharani, Ameen M, Abraham S, Job V, et al. A double-blind, randomized, multicenter study evaluating the effects of pioglitazone in fasting Muslim subjects during Ramadan; 2006.

25. Sherifali D, Nerenberg K, Pullenayegum E, Cheng JE, Gerstein HC. The effect of oral antidiabetic agents on A1C levels: a systematic review and meta-analysis. Diabetes Care. 2010 Aug;33(8):1859-64.

26. Hirst JA, Farmer AJ, Dyar A, Lung TW, Stevens RJ. Estimating the effect of sulfonylurea on HbA1c in diabetes: a systematic review and meta-analysis. Diabetologia. 2013 May;56(5):973-84.

27. Mafauzy M. Repaglinide versus glibenclamide treatment of Type 2 diabetes during Ramadan fasting. Diabetes Res Clin Pract. 2002 Oct;58(1):45-53.

28. Sari R, Balci MK, Akbas SH, Avci B. The effects of diet, sulfonylurea, and Repaglinide therapy on clinical and metabolic parameters in type 2 diabetic patients during Ramadan. Endocr Res. 2004 May;30(2):169-77.

29. Aravind SR, Al Tayeb K, Ismail SB, Shehadeh N, Kaddaha G, Liu $\mathrm{R}$, et al. Hypoglycaemia in sulphonylurea-treated subjects with type 2 diabetes undergoing Ramadan fasting: a five-country observational study. Curr Med Res Opin. 2011 Jun;27(6):1237-42.

30. Belkhadir J, el Ghomari H, Klocker N, Mikou A, Nasciri M, Sabri M. Muslims with non-insulin dependent diabetes fasting during Ramadan: treatment with glibenclamide. BMJ. 1993 Jul;307(6899): 292-5.

31. Devendra D, Gohel B, Bravis V, Hui E, Salih S, Mehar S, et al. Vildagliptin therapy and hypoglycaemia in Muslim type 2 diabetes patients during Ramadan. Int J Clin Pract. 2009 Oct;63(10):1446-50.

32. Al-Arouj M, Hassoun AA, Medlej R, Pathan MF, Shaltout I, Chawla MS, et al. The effect of vildagliptin relative to sulphonylureas in Muslim patients with type 2 diabetes fasting during Ramadan: the VIRTUE study. Int J Clin Pract. 2013 Oct;67(10):957-63.

33. Al Sifri S, Basiounny A, Echtay A, Al Omari M, Harman-Boehm I, Kaddaha $G$, et al. The incidence of hypoglycaemia in Muslim patients with type 2 diabetes treated with sitagliptin or a sulphonylurea during Ramadan: a randomised trial. Int J Clin Pract. 2011 Nov;65(11):1132-40.

34. Faruque Pathan M, Feroz Amin M, Afsana F, Saghir Abdur Rahim M, Jahangir Alam Sarker M, Mobarak Ali T, et al. Efficacy and Safety of Vildagliptin Compared to Sulphonylurea in Patients with Type 2 Diabetes during Fasting in Ramadan; 2016.

35. Zinman B, Wanner C, Lachin JM, Fitchett D, Bluhmki E, Hantel S, et al. Empagliflozin, Cardiovascular Outcomes, and Mortality in Type 2 Diabetes. N Engl J Med. 2015 Nov 26;373(22):2117-28.

36. Furtado Remo HM, Bonaca Marc P, Raz I, Zelniker Thomas A, Mosenzon O, Cahn A, et al. Dapagliflozin and Cardiovascular Outcomes in Patients With Type 2 Diabetes Mellitus and Previous Myocardial Infarction. Circulation. 2019 May 28;139(22):2516-27. 
37. Wiviott SD, Raz I, Bonaca MP, Mosenzon O, Kato ET, Cahn A, et al. Dapagliflozin and Cardiovascular Outcomes in Type 2 Diabetes. N Engl J Med. 2018 Jan 24;380(4):347-57.

38. Neal B, Perkovic V, Mahaffey KW, de Zeeuw D, Fulcher G, Erondu $\mathrm{N}$, et al. Canagliflozin and Cardiovascular and Renal Events in Type 2 Diabetes. N Engl J Med. 2017 Aug 17;377(7):644-57.

39. Perkovic V, Jardine MJ, Neal B, Bompoint S, Heerspink HJL, Charytan DM, et al. Canagliflozin and Renal Outcomes in Type 2 Diabetes and Nephropathy. N Engl J Med. 2019 Jun 13;380(24):2295-306.

40. Wanner C, Inzucchi SE, Lachin JM, Fitchett D, von Eynatten M, Mattheus M, et al. Empagliflozin and Progression of Kidney Disease in Type 2 Diabetes. N Engl J Med. 2016 Jul 28;375(4):323-34.

41. Mosenzon O, Wiviott SD, Cahn A, Rozenberg A, Yanuv I, Goodrich EL, et al. Effects of dapagliflozin on development and progression of kidney disease in patients with type 2 diabetes: an analysis from the DECLARE\&\#x2013;TIMI 58 randomised trial. Lancet Diabetes Endocrinol. 2019 Aug;7(8):606-617.

42. Shao Y, Lim GJ, Chua CL, Wong YF, Yeoh ECK, Low SKM, et al. The effect of Ramadan fasting and continuing sodium-glucose co-transporter-2 (SGLT2) inhibitor use on ketonemia, blood pressure and renal function in Muslim patients with type 2 diabetes. Diabetes Res Clin Pract. 2018 Aug;142:85-91.

43. Bashier A, Khalifa AA, Abdelgadir EI, Al Saeed MA, Al Qaysi AA, Bayati MBA, et al. Safety of Sodium-Glucose Cotransporter 2 Inhibitors (SGLT2-I) During the Month of Ramadan in Muslim Patients with Type 2 Diabetes. Oman Med J. 2018 Mar;33(2):104-10.

44. Brady EM, Davies MJ, Gray LJ, Saeed MA, Smith D, Hanif W, et al. A randomized controlled trial comparing the GLP-1 receptor agonist liraglutide to a sulphonylurea as add on to metformin in patients with established type 2 diabetes during Ramadan: the Treat 4 Ramadan Trial. Diabetes Obes Metab. 2014 Jun;16(6):527-36.

45. Azar ST, Echtay A, Wan Bebakar WM, Al Araj S, Berrah A, Omar $\mathrm{M}$, et al. Efficacy and safety of liraglutide compared to sulphonylurea during Ramadan in patients with type 2 diabetes (LIRA-Ramadan): a randomized trial. Diabetes Obes Metab. 2016 Oct;18(10):1025-33.

46. Bashier A, Bin Hussain A. Azza AK Bin Hussain, Ali O El Rashid and Alaaeldin MK Bashier. Safety and Efficacy of Liraglutide as an Add-On Therapy to Pre-Existing Anti-Diabetic Regimens during
Ramadan, A Prospective Observational Trial. J Diabetes Metab 2015, 6:9 http://dx.doi.org/10.4172/2161-1122.1000590; 2015.

47. Grunberger G. Insulin analogs-are they worth it? Yes! Diabetes Care. 2014 Jun;37(6):1767-70.

48. Cesur M, Corapcioglu D, Gursoy A, Gonen S, Ozduman M, Emral R, et al. A comparison of glycemic effects of glimepiride, repaglinide, and insulin glargine in type 2 diabetes mellitus during Ramadan fasting. Diabetes Res Clin Pract. 2007 Feb;75(2):141-7.

49. Bakiner O, Ertorer ME, Bozkirli E, Tutuncu NB, Demirag NG. Repaglinide plus single-dose insulin glargine: a safe regimen for low-risk type 2 diabetic patients who insist on fasting in Ramadan. Acta Diabetol. 2009 Mar;46(1):63-5.

50. Salti I, Diabetes, Ramadan Study G. Efficacy and safety of insulin glargine and glimepiride in subjects with Type 2 diabetes before, during and after the period of fasting in Ramadan. Diabet Med. 2009 Dec;26(12):1255-61.

51. Hassanein M, Echtay AS, Malek R, Omar M, Shaikh SS, Ekelund M, et al. Original paper: Efficacy and safety analysis of insulin degludec/ insulin aspart compared with biphasic insulin aspart 30: A phase 3, multicentre, international, open-label, randomised, treat-to-target trial in patients with type 2 diabetes fasting during Ramadan. Diabetes Res Clin Pract. 2018 Jan;135:218-26.

52. Mattoo V, Milicevic Z, Malone JK, Schwarzenhofer M, Ekangaki A, Levitt LK, et al. A comparison of insulin lispro Mix25 and human insulin 30/70 in the treatment of type 2 diabetes during Ramadan. Diabetes Res Clin Pract. 2003 Feb;59(2):137-43.

53. Shehadeh N, Maor Y, Ramadan Study G. Effect of a new insulin treatment regimen on glycaemic control and quality of life of Muslim patients with type 2 diabetes mellitus during Ramadan fast - an open label, controlled, multicentre, cluster randomised study. Int J Clin Pract. 2015;69(11):1281-8.

54. Akram J, De Verga V. Insulin lispro (Lys(B28), Pro(B29) in the treatment of diabetes during the fasting month of Ramadan. Ramadan Study Group. Diabet Med. 1999 Oct;16(10):861-6.

55. Pathan MF, Sahay RK, Zargar AH, Raza SA, Khan AK, Ganie MA, et al. South Asian Consensus Guideline: Use of insulin in diabetes during Ramadan. Indian J Endocrinol Metab. 2012 Jul;16(4):499-502. 